\title{
Development of a national burn network: providing a co-ordinated response to a burn mass casualty disaster within the Australian health system
}

\author{
F Wood', D Edgar', and AG Robertson ${ }^{3}$ \\ ${ }^{1}$ Western Australian Burns Service, Royal Perth Hospital and Princess Margaret Hospital for Children, Perth, Western Australia, Australia; \\ ${ }^{2}$ Telstra Burns Rehabilitation and Outcomes Unit, Royal Perth Hospital, Perth, Western Australia, Australia; and ${ }^{3}$ Health Protection Group, \\ Western Australian Department of Health, Perth, Western Australia, Australia.
}

\author{
Correspondence \\ Dale Edgar, Telstra Burns \\ Rehabilitation and Outcomes Unit, \\ Wellington St Campus, Royal Perth \\ Hospital, Perth, Western Australia \\ 6847, Australia.
}

Received 20 November 2006

Revised 4 March 2007

Accepted 11 May 2007

\begin{abstract}
With the threat of terrorist activity ever present since the incidents in Bali and Jakarta, the Australian health system must be prepared to manage another mass burn casualty disaster. The Australian and New Zealand Burns Association (ANZBA) highlighted the lack of a national burn disaster response before the 2000 Olympics. With the limited number of burn beds available and the protracted length of stay after such injuries, any state or territory could be overwhelmed with relatively few patient admissions. In 2002, the Australian Health Minister's Conference called for a solution. The objective of this paper is to provide an overview of the process and development of the Australian National Burn Network, which underpins the National Burn Disaster Response (AUSBURNPLAN).
\end{abstract}

\section{Introduction}

\section{"The quality of outcome must be worth the pain of survival." 1}

Burn care has progressed greatly over the past 70 years. Many advances were related to episodes of conflict, with significant progress in the quality of burn care seen during the Second World War. The introduction of appropriate first aid ensured that burn injuries involving more than one-third of the body surface area were not uniformly fatal, which was the case even for young men in that era. The 1950s and 1960s saw major advances made in fluid resuscitation, medical treatment, and infection control for burn injury. Further improvement in skin grafting techniques also reduced mortality. ${ }^{2,3}$ In the 1970s and 1980s, advances were made in the treatment of massive burn injuries. These were associated with early burn excision and were combined with techniques to reduce blood loss and improved facilities for patient isolation and infection control. ${ }^{4}$ Improvement in mortality rates continued with the development of intensive care techniques, the management of inhalation injury, and the manipulation of the hypermetabolic response. ${ }^{5}$

Dedicated well-equipped burn facilities provide the best outcomes for burn patients, with the focus not just limited to survival. ${ }^{4}$ Outcome after burn injury is no longer simply measured by mortality rates. Burn survivor outcomes are now debated in the literature in terms of rehabilitation of function and restoration of quality of life. The unique nature and long-term sequelae of burn injury are made more complex by the fact that, while in hospital, $84 \%$ of major burn patients suffer 'severe or excruciating pain', 100\% suffer daily pain, and $92 \%$ are woken at night with pain, in nondisaster circumstances. ${ }^{6}$ Today, tertiary care burn units maintain standards and staffs' expertise levels owing to their significant patient throughput. ${ }^{7}$

In Australia, there are only 12 dedicated burn care facilities (including both adult and paediatric) with sufficient numbers of burn patients and facilities to maintain such standards. In contrast to the USA, a formal process to monitor or maintain burn service standards is not in place in Australia. Furthermore, burn services are situated in state capital cities, and, as a result, the routine management of burn survivors may be complicated by prolonged patient transfer times. These arrangements, combined with the regular threat of bushfires and increasing terrorist activity, prompted the Australian Government in 2002 to formalise specific prevention, preparedness, recovery, and response plans for Australian mass burn casualties, as part of a comprehensive, all-agency approach. ${ }^{8}$

In the mass casualty situation, Hirshberg et al. ${ }^{9}$ suggest that the arrival of three to five severely injured burn patients

OAccess This is an Open Access article distributed under the terms of the Creative Commons Attribution licence which permits unrestricted use, distribution, and OPEN - access reproduction in any medium, provided the original work is properly cited. 
in a major urban trauma centre necessitates the mobilisation of resources outside the routine trauma response. A mass casualty incident, with as few as 30 injured, would typically generate three to five severely burned survivors. ${ }^{10}$ Disasters, by definition, overwhelm existing resources and require coordination and the mobilisation of clinical expertise, particularly in isolated areas. In Australia, without the involvement of the Australian Defence Force (ADF), the current capacity and availability of civilian aeromedical evacuation transport would provide timely transfer for fewer than 10 casualties at any one time, leading to relative isolation of significant numbers of the population in the event of a disaster. ${ }^{10,11}$ Therefore, to achieve optimal burn casualty evacuation and isolated site management, it is vital to include appropriately trained multidisciplinary burn teams in the planning and practical response to such an event.

\section{Identifying risk}

Following Exercise Icarus, a mock burn disaster exercise and aeromedical evacuation from the Northwest Shelf off Western Australia (WA), a submission was made from WA to the Australian Health Ministers' Conference (AHMC) in July 2002 to establish a national response strategy to a burn mass casualty situation. In October 2002, the Bali terrorist bombing further highlighted that Australia's burn disaster response strategy required formalisation. Subsequently, with the support of the Australian Government, the National Burn Planning and Coordination Committee (NBPCC) was established and met for the first time in March 2003. This resulted in two working parties being convened, the National Burn Response Plan Working Party, chaired by New South Wales (NSW) Health representatives, and the National Burn Training and Standards Working Party, chaired by WA representatives.

\section{Burn disaster preparedness: policy development} The Australian Health Minister's Advisory Council (AHMAC) and State and Territory Health Departments funded the NBPCC. This Committee was the central point of review and discussion, formally meeting over an 18-month timeframe to address the following aims:

1. review available literature for mass casualty burn disaster management and for standards of specialised burn care (staffing and facilities);

2. assemble multidisciplinary experts to assimilate the literature into guidelines for practice; and

3. disseminate the information and promote action on the recommendations.

Key stakeholders and burn management experts represented on the NBPCC committee and working parties included the Australian Health Disaster Management Policy Committee (AHD-MPC), Emergency Management Australia (EMA), ADF, Royal Australian College of Surgeons (RACS),
Department of Health and Ageing (DoHA), Australian and New Zealand Burns Association (ANZBA), and adult and paediatric burn service directors from all Australian states and territories and New Zealand.

Two project officers, one for each working party, were appointed, with administrative support, to collate documents and review the literature. The NBPCC met three times to determine the development strategy, working party members, and to discuss and finalise the two documents. The working groups met a further one or two times each to develop consensus and the practical plan for activation and maintenance of a national burn disaster response within the limitations of state and territory health jurisdictions. E-mail discussion, translated by the project officers into documents, was the primary method for feedback, engagement, and consensus, because the papers were used as the basis for discussion at each formal group meeting.

\section{Optimising the Australian National Burn Disaster Response}

The framework used to develop, maintain, and implement a co-ordinated emergency response in the case of mass burn casualties was Prevention, Preparedness, Response, and Recovery. ${ }^{8}$ The AUSBURNPLAN ${ }^{10}$ dealt primarily with preparedness and response, whereas the National Model of Burn Care (NMOBC) ${ }^{12}$ documented burn prevention (education and training) and recovery strategies. The two documents were not mutually exclusive and were generated collaboratively with all stakeholders' feedback taken into consideration.

\section{National Burn Disaster Plan}

In July 2004, the AHMC endorsed the AUSBURNPLAN, which provides the strategy for an optimal national response during both the acute and the protracted recovery phases of a disaster involving burns on Australian soil. In instances in which burn trauma survivors are repatriated from jurisdictions outside Australia, the AUSBURNPLAN dovetails into the EMA national plans, including the Overseas Mass Casualty Plan ${ }^{13}$ and Commonwealth Disaster Plan. ${ }^{14}$

The primary aim of the AUSBURNPLAN is to reduce parallel communication by describing the roles of all agencies involved in the event of a burn disaster response. The plan describes mass burn casualty management in the following way by means of colour-coded phases: Code White (Alert Phase), Code Yellow (Standby Phase), Code Red (Callout Phase), and Green Phase (Standown Phase). The Callout Phase is further broken down as follows:

- Phase 1 (Surge Phase): an acute surge in demand inevitably beyond the State or Territory's ability to provide core business services (p25). ${ }^{10}$ The AUSBURNPLAN must be activated through the local state disaster planners in the event of a burn disaster (suggested threshold for activation $\sim 20$ severely burned survivors). 
- Phase 2 (Redistribution Phase): a protracted period of occupancy for each severely burned patient that will overextend the capability of the burn service to manage effectively (p28). ${ }^{10}$ In Phase 2 , national co-ordination will be important. When activated, AUSBURNPLAN provides a framework for redistribution of patient loads across Australia, overcoming State health jurisdictional issues, such as registration of health professionals to practise outside their home state or territory. Local challenges arise with the protracted length of stay and complexity of ongoing severe burn management (for example, 12-16 weeks for an $80 \%$ burned patient). One of the recommendations of the AUSBURNPLAN is the appointment of a national burn disaster co-ordinator who would chair and direct the National Burn Network (NBN) described in the NMOBC.

\section{National Model of Burn Care}

The successful implementation and maintenance of the NBPCC-derived burn disaster plans hinge on the formalisation and sustained function of the NBN. The NMOBC details the NBN as the linkage between burn health professionals and the disaster planners. It will supersede the NBPCC and consists of representatives of each State or Territory Burn Service, the Australian Health Protection Committee (which replaced AHDMPC), and ANZBA (including medical, nursing, and allied health representatives). The Co-ordinator, as noted above, is a clinical expert in burn and disaster management, and is the key liaison between the Australian Government, national health disaster planners, burn clinicians, and, most importantly, the Australian public, in the event of AUSBURNPLAN activation.

\section{Standards and training}

The current provision of specific burn care across Australia is variable in terms of organisation, staffing, facilities, and workload. A key aspect of the NMOBC is the discussion of burn unit standards and staff training necessary to optimally manage severe burns and effective activation of AUSBURNPLAN. Clinicians must be trained in disaster management and be aware of their specific roles and responsibilities in any level of disaster response. ${ }^{15}$ The NMOBC was endorsed by AHDMPC in December 2004 and details:

- minimum Australian standards for burn units, including asset stockpiles and disaster plans;

- current burn and disaster management training opportunities;

- gaps in available training opportunities with respect to disaster preparedness;

- minimum training requirements to provide staff with the tools to action AUSBURNPLAN surge and recovery phases; and

- costing and strategies required to develop a national burn staff standards and training programme.
The NMOBC also recommended that a national burn database be developed to support the NBN. To expedite the development of this project, it was championed by ANZBA and has undergone a process of national burn unit synthesis, training and is now marked to expand. All burn services in Australia (and eventually New Zealand) now provide information to this system. At present, the system provides injury prevalence and severity data used to plan more efficient and effective burn prevention programmes. As the system progresses to full capabilities, it will incorporate the 'real-time' identification of burn care capacity and resource availability to inform national disaster planning in support of a mass casualty incident response. The UK experience with the National Burn Injury Database has been positive, with the provision of burn bed and hospital emergency medicine capacity data. ${ }^{16}$

The future aim, in liaison with the Australian Council for Healthcare Standards (ACHS) and RACS Trauma Service Verification Committee, is that all recommendations of the NMOBC will be formalised for accreditation of healthcare services that wish to manage burn (disaster) survivors. This will be a task led by the NBN and supported by ANZBA.

Outside the scope of recommendations, but of great importance, the education strategies proposed in the NMOBC engage the community in accepting responsibility for selfmanagement in the event of a burn disaster. To optimise burn survivor outcomes through pre-hospital care, the general population must also be trained in first aid and disaster survival techniques. Various avenues are currently being examined by members of the NBN to tackle this important task.

\section{Conclusion}

In the event of a mass casualty burn incident, burn specialists will be included in the planning and response to such a scenario, through arrangements articulated in AUSBURNPLAN. The literature clearly outlines that burn patient outcomes are enhanced when burn-specific treatment and transfer procedures are applied promptly. In the long-term, patient outcomes are also significantly enhanced by treatment in suitably designed specialist burn facilities, particularly those having designated isolation facilities and the infrastructure to support the critically ill patient. A minimum level of education and training for staff involved in burn care is also clearly linked to optimal patient outcomes and disaster preparedness, both relating to the core burn care and disaster response scenario. In addition, training the Australian community will further enhance burn trauma care in the important pre-hospital timeframe. These aspects are incorporated in the standards of the NMOBC. The NBN has a key role in ensuring that this strategy advances.

\section{Acknowledgements}

The authors would like to recognise the contribution of all members of the working parties established to develop the AUSBURNPLAN and the National Burns Network Education and Standards documents. 


\section{Author contributions}

All authors contributed equally to the development, intellectual concepts, and writing of this paper.

\section{Competing Interests}

AG Robertson is the Editor-in-Chief of the Emerging Health Threats Journal. He was blinded to the entire peer-review and decision-making process on this manuscript. No other conflict of interest exists among any of the authors.

\section{Funding}

D Edgar was seconded from the Royal Perth Hospital Burns Unit and Physiotherapy Department to document the National Burns Network Education and Standards for the Western Australian Department of Health through funds from the Federal Government of Australia.

\section{Provenance}

Not commissioned; externally peer-reviewed.

\section{References}

1 Wood FM. Quality assurance in burn patient care: the James Laing Memorial Essay-1994. Burns 1995;21:563-8.

2 Munster AM, Smith-Meek M. The effect of early surgical intervention on mortality and cost effectiveness in burn care 1978-1991. Burns 1994;20:61-4.

3 Thomas S, Barrow RE, Herndon DN. Introduction: history of the treatment of burns. In: Herndon DN (ed). Total Burn Care, 2nd edn. Saunders: London, 2002, pp 1-1.

4 Herndon DN, Blakeney PE. Chapter 1 - Teamwork for total burn care: achievements, directions and hopes. In: Herndon DN (ed). Total Burn Care, 2nd edn. Saunders: London, 2002, pp 11-15.

5 Sheridan R, Weber J, Prelack K, Peteras L, Lydon M, Tompkins R. Early burn centre transfer shortens the length of hospitalisation and reduces complications in children with serious burn injuries. J Burn Care Rehab 1999;20:347-50.

6 Montgomery RK. Pain management in burn injury. Crit Care Nurs Clin North Am 2004;16:39-49.

7 Curreri PW, Luterman A, Braun DW Jr, Shires GT. Analysis of survival and hospitalization time for 937 patients. Ann Surg 1980;192:472-8.

8 Emergency Management Australia (EMA). Australian Emergency Manual. Updates 2004. Available at http://www.ema.gov.au, accessed 20 November 2005

9 Hirshberg A, Holcomb JB, Mattox KL. Hospital trauma care in multiple-casualty incidents: a critical review. Ann Emerg Med 2001;37:647-52.

10 Hovarth J. AUSBURNPLAN-Australian Mass Casualty Burn Disaster Plan. Available at http://www.health.gov.au/internet/ wcms/publishing.nsf/Content/phd-health-emergency.htm, accessed 13 November 2006. Cooper D, Campbell P (eds), 2005.

11 Palmer DJ, Stephens D, Fisher DA, Spain B, Read DJ, Notaras L. The Bali bombing: the Royal Darwin Hospital response. Med J Aust 2003;179:358-61.

12 Robertson AG, Wood F, Edgar D. Development of a National Model of Care for Burn Patients. Western Australian Department of Health: Perth, 2004.

13 Emergency Management Australia (EMA). OSMASSCASPLAN in Critical Infrastructure Emergency Risk Management and Assurance Handbook. 2nd edn. May 2004; p 65. Available at http:// www.ema.gov.au/agd/EMA/rwpattach.nsf/VAP/(63F21BC6A4528 BAE4CED2F9930C45677) CIERM2004.pdf/\$file/CIERM2004.pdf, accessed 19 February 2007.

14 Emergency Management Australia (EMA). COMDISPLAN; 2002. Available at http://www.ema.gov.au/agd/ema/emaInternet.nsf/ Page/RWP51590DE2C3F9ACE6CA256C48001A3416?OpenDocument, accessed 19 February 2007.

15 Lee WH, Chiu TF, Ng CJ, Chen JC. Emergency medical preparedness and response to a Singapore airliner crash. Acad Emerg Med 2002;9:194-8.

16 Dunn K. Standards and strategy for burn care: a review of burn care in the British Isles. National Burn Care Burn ReviewCommittee Report 2000. p 52. 